\title{
Graduate Finalists Compete for Awards at 1992 MRS Fall Meeting
}

At the 1992 MRS Fall Meeting in Boston, 27 finalists will compete for the MRS Graduate Student Awards, to be presented on Thursday evening during ceremonies also honoring the 1992 Von Hippel and MRS Medalist recipients.

Graduate Award Finalists, all authors or co-authors of papers to be presented at the Fall Meeting, were selected on the basis of the quality and thoroughness of their re- search, the originality and independence of their contributions, and their promise for future achievement in materials research.

During three special sessions on Thursday, December 3, the finalists will give brief talks explaining their research to a panel of judges who will select the award recipients. Among the judges will be orga- nizers from the symposia in which the finalists are participating, members of the MRS Awards Committee, and other MRS representatives. MRS Fall Meeting participants are also invited to attend.

Following is a list of the finalists, where they are studying, the titles of their papers, and the symposium in which each is participating.

\section{Graduate Student Award Finalists 1992 MRS Fall Meeting}

Qing Zhu, University of Pennsylvania, "Selective Site Occupancy in $\mathrm{C}_{60}$ Intercalation Compounds: Identification of a Rocksalt Phase at $x=1\left(\mathrm{M}_{1} \mathrm{C}_{61,}, \mathrm{M}=\mathrm{K}\right.$, $\mathrm{Rb}, \mathrm{Cs}$ )" (Symposium AA)

Ram Devanathan, Argonne National Laboratory, "Molecular Dynamics Simulation of Radiation-Induced Amorphization of the Ordered Compound NiZr, (Symposium A)

Lisa M. Spellman-Porter, North Carolina State University, "High Spatial Resolution TEM Study of Thin Film Metal/6H-SiC Interfaces"

(Symposium B)

Ian M. Anderson, University of Minnesota, "Equilibrium Sub-Micrometer-

Scale High-Temperature Microstructures in the System $\mathrm{NiO}^{-\mathrm{TiO}_{2}}{ }^{\prime \prime}$

(Symposium C)

Chengheng R. Kao, University of Wisconsin, "A Theoretical Analysis on the Relative Stability Between Simple Layered Structure and Periodic Layered Structure in Ternary Diffusion Couples" (Symposium C)

Jennifer A. Sees, University of North Texas, "Composite Solders: Diffusion Kinetics and Microstructural Examination of Intermetallic Layers"

(Symposium C)

Susan Zonglu Hua, University of Maryland, "Trapping and Luminescence Mechanism Studies in SrS: $\mathrm{Eu}^{2+}, \mathrm{Sm}^{3+}$ Thin Film at Various Temperatures" (Symposium D)

Richard G. Purser, Cornell University, "Electrical Contacts to $\mathrm{Si}_{1-\mathrm{x}} \mathrm{Ge}_{\mathrm{x}}$ Using $\mathrm{Pd}_{2} \mathrm{Si}$ As a Transport Layer" (Symposium D)

Rodrigo R. Rubiano, Massachusetts Institute of Technology, "Low Temperature Deposition of Zirconium Carbide Films From Single Source Precursor" (Symposium E)
Masanori Otobe, Tokyo Institute of Technology, "Separation of Nucleation and Growth Process of Nanocrystalline Si by Hydrogen Radical Treatment of aSi:H" (Symposium F)

John A. Rogers, Massachusetts Institute of Technology, "Non-Contact Real-Time Evaluation of Polyimide Thin Film Thermoelastic Properties Through Impulsive Stimulated Thermal Scattering" (Symposium G)

Xiao Zhang, The University of Tennessee, "Electron Holographic Characterization of Ferroelectric Thin Films" (Symposium G)

Alejandro Chang, Polytechnic University, "Tunneling and Scanning Tunneling Spectroscopies as Tools for Characterizing Superconductors" (Symposium H)

Lance D. Cooley, University of Wisconsin, "Experimental Evidence for the Matching of the Fluxon Lattice to a Highly Uniform Arrangement of Pins" (Symposium $\mathrm{H}$ )

Joel Mesot, ETH Zürich and Paul Scherrer Institut, "Crystal Field, Charge Transfer, Cluster Formation and Percolative Superconductivity in $\mathrm{RBa}_{2} \mathrm{Cu}_{3} \mathrm{O}$ 、 $(\mathrm{R}=\text { rare earth, } 6 \leqslant x \leqslant 7)^{\prime \prime}$ (Symposium $\mathrm{H}$ )

Ashwin K. Ballal, University of Maryland, "Preferentially Oriented Cubic Boron Nitride Films Grown on Si(001) Substratres by Ion Assisted Pulsed Laser Deposition" (Symposium I)

Harvey M. Phillips, Rice University, "Excimer Laser Induced Mechanical and Electrical Nanostructures in Polymers" (Symposium I)

Chrysanthe D. Terwilliger, Massachusetts Institute of Technology, "Excess Thermodynamic Properties of Nanophase Titanium Dioxide Prepared by Chemical and Physical Methods" (Symposium J)
Zhongjian Chen, SUNY, "Characterization of Vacuum Plasma Sprayed Mechanofused NiAl" (Symposium L)

Shaoyi Jiang, Cornell University, "Computer Simulation Study of Adsorption, Isosteric Heat and Phase Transition of Methane on Graphite" (Symposium N)

William M. Tong, University of California-Los Angeles, "Analysis of Scaling Phenomena in Thin Film Growth With An Atomic Force Microscope" (Symposium P)

Y. Z. Chu, Columbia University, "Adhesion Study of Interface Formation Between Immiscible Polymers"

(Symposium Q)

Nicholas Camillone III, Princeton University, "Superlattice Structure at the Surface of Monolayers of $n$-Alkane Thiols Self-Assembled on Au(111) as Measured by Helium Atom Diffraction" (Symposium R)

Navjot Singh, University of Minnesota, "Phase Transitions in Diblock Copolymer Films" (Symposium R)

Shelli R. Letellier, University of Washington, "Assessing the Quality of Langmuir-Blodgett and Self-Assembled Films Using Angular Resolved ESCA" (Symposium S)

Catherine Heremans, Massachusetts Institute of Technology, "Fast-Ion Conduction and Disorder in Cation and Anion Arrays in $\mathrm{Y}_{2}\left(\mathrm{Zr}_{\times} \mathrm{Ti}_{1-x}\right)_{2} \mathrm{O}_{7}$ Pyrochlores Induced by $\mathrm{Zr}$ Substitution: $\mathrm{A}$

Rietveld Neutron Analysis"

(Symposium U)

V. Ravikumar, Northwestern University,

"Determination of the Geometric,

Chemical and Electronic Structure of Tilt

Grain Boundaries in Doped and Undoped $\mathrm{SrTiO}_{3}$ " (Symposium W) 